\title{
OS DESAFIOS DA AGRICULTURA FAMILIAR FRENTE AOS PROGRAMAS DE COMPRAS PÚBLICAS DE ALIMENTOS: UM ESTUDO SOBRE AGRICULTORES DA REGIÃO SUDOESTE DO ESTADO DE SÃO PAULO
}

Daniel Bertoli GONÇALVES*

*Professor e Pesquisador do Programa de Pós-Graduação em Processos Tecnológicos e Ambientais Mestrado Profissional, Universidade de Sorocaba. danielbertoli@bol.com.br

Recebido em: 27/05/2014 - Aprovado em: 30/06/2014 - Disponibilizado em: 30/07/2014

RESUMO

No Brasil, a agricultura familiar é responsável pela maior parte dos alimentos que chegam a mesa da população, apesar do fraco apoio estatal recebido ao longo de sua história. No intuito de oferecer melhores oportunidades a esse segmento, um conjunto de políticas foi criado a partir do Programa Nacional de fortalecimento da Agricultura Familiar (Pronaf), de 1996. Entre as mais recentes estratégias de apoio figuram programas de compras estatais diretas, que abriram o mercado institucional para os produtos da agricultura familiar. Através de uma pesquisa documental e de campo, este estudo buscou discutir essa abertura diante da perspectiva de 10 associações e cooperativas de agricultores familiares da região sudoeste do estado de São Paulo. Verificou-se que ao garantir uma parcela importante da renda anual dos agricultores, tais políticas estão alcançando resultados positivos, trazendo boas perspectivas para o setor.

Palavras chave: Agricultura familiar, compras públicas, desenvolvimento regional, alimentação escolar, políticas públicas.

\section{THE CHALLENGES OF FAMILY FARM FRONT OF PROGRAMS PUBLIC PROCUREMENT OF FOOD: A STUDY OF FARMERS IN THE REGION SOUTHWEST OF SÃO PAULO}

\begin{abstract}
Family farming in Brazil has been responsible for most foods that come to the table of the population, despite the weak state support it has received throughout its history. In order to offer better opportunities to this segment, a set of policies was created by the National Program for Strengthening Family Agriculture (PRONAF), in 1996. Among the latest strategies to support this initiative there are the direct state purchasing programs, which paved the institutional market for the products of the family farm. This study discusses the opening of this perspective of 10 associations and cooperatives of small farmers in the southwest region of the state of São Paulo. It was found that, by securing a significant portion of the annual income of farmers involved in the project, such policies are achieving positive results, and good prospects.
\end{abstract}

Keywords: Family farm, public purchases, regional development, school feeding, public policy.

\section{Introdução}

A demanda por gêneros alimentícios no Brasil, atualmente dividida entre consumidores finais, empresas, restaurantes, instituições públicas e privadas, é caracterizada por uma grande variedade de produtos que vai dos frescos, como frutas, legumes e hortaliças, até os alimentos processados e prontos para o consumo, passando por uma gama enorme de laticínios, embutidos, grãos, carnes, entre tantos 
outros, cuja oferta pode ser caracterizada pela predominância de empresas ligadas ao agronegócio, cooperativas de pequenos e médios produtores, além de distribuidores de produtos importados.

Apesar de boa parte desta relação entre oferta e demanda ocorrer através dos canais tradicionais de comercialização, tais como feiras livres, quitandas e supermercados, uma parcela significativa da demanda, formada pelas compras públicas direcionadas às instituições administradas ou amparadas pelas diferentes instâncias de governo, era dominada, até a década de 1990, pelos grandes distribuidores e empresas alimentícias ligadas ao agronegócio. Um domínio que se consolidou com a Lei 8.666 de 1993, que ao estabelecer a obrigatoriedade do procedimento licitatório para toda contratação, aquisição, venda ou alienação em órgãos públicos, acabou por restringir o acesso dos pequenos produtores a esse mercado.

$\mathrm{Na}$ tentativa de abrir uma parcela do mercado institucional para a agricultura familiar, em continuidade ao Programa Nacional de fortalecimento da Agricultura Familiar - PRONAF, de 1996, foi criado em 2001, também pelo governo federal, o Programa de Aquisição de Alimentos - PAA, que inicialmente previa dois mecanismos que seriam operados pela Companhia Nacional de Abastecimento - CONAB ou diretamente pelos governos federal, estadual ou municipal: A compra para formação de estoques públicos de alimentos, medida rotineira executada pelos governos visando preservar a estabilização dos preços, e a compra com doação simultânea para programas de combate à fome e a insegurança alimentar em determinadas localidades. Nesse último caso, a compra era feita junto aos agricultores, respeitando-se as determinações da Lei das Licitações (Lei 8.666/93), e entregue às instituições de caridade, hospitais e principalmente ao PNAE - Programa Nacional da Alimentação Escolar.

Em 2008, o FNDE - Fundo Nacional para o Desenvolvimento da Educação, repassador dos recursos do PNAE aos municípios passou a autorizar a utilização desses recursos por parte das prefeituras para a compra direta junto aos produtores familiares, que após a regulamentação da Lei $\mathrm{n}^{\circ}$ 11.947 em 2009, passou a oferecer uma segunda abertura no mercado institucional para os agricultores familiares que já contavam com o PAA.

Em outubro de 2011 o governo do estado de São Paulo passou a oferecer uma terceira opção para esses agricultores, com a criação do Programa Paulista da Agricultura de Interesse Social - PPAIS, através do qual os órgãos do Estado deveriam empregar, no mínimo, trinta por cento dos recursos destinados à aquisição de gêneros alimentícios, in natura ou manufaturados, para hospitais públicos, presídios, escolas públicas, instituições de amparo social e outras entidades, na compra direta, mediante chamada pública, da produção da agricultura familiar.

Este estudo discute esta abertura do mercado institucional diante da perspectiva de 15 associações e cooperativas de agricultores familiares da região sudoeste do estado de São 
Paulo, de forma a apontar as dificuldades e os benefícios que tais políticas estariam trazendo aos agricultores envolvidos.

Para isso o trabalho está estruturado em uma pesquisa bibliográfica, cujo objetivo é oferecer um contexto histórico e conceitual para o tema, seguida dos resultados de uma pesquisa de campo na qual foram coletadas informações quantitativas $\mathrm{e}$ qualitativas através de visitas e entrevistas semiestruturadas junto as cooperativas e associações de agricultores familiares da região.

\section{O agronegócio e a produção familiar}

A agricultura brasileira tem se dividido ao longo de sua história entre o suprimento da demanda por alimentos e o fornecimento de matéria prima para alguns ramos da indústria. Com o passar do tempo, e em meio a controversas opções políticas e econômicas, este setor foi se segmentando em algumas atividades, cujos extremos se consolidaram como agronegócio, de um lado, e pequena produção familiar, de outro.

Segundo Callado (2006), o agronegócio pode ser definido como um conjunto de empresas que produzem insumos agrícolas, as propriedades rurais, as empresas de processamento e toda a distribuição. No Brasil o termo é usado quando se refere a um tipo especial de produção agrícola, caracterizada pela agricultura em grande escala, baseada no plantio ou na criação de rebanhos e em grandes extensões de terra. Estes negócios, no geral, se fundamentam na propriedade latifundiária bem como na prática de arrendamentos.

Segundo a Confederação Nacional da Agricultura - CNA, o agronegócio é o maior negócio mundial e brasileiro. No mundo, representa a geração de U\$ 6,5 trilhões/ano e, no Brasil, em torno de $\mathrm{R} \$ 942$ bilhões em 2011, sendo responsável por $22,7 \%$ do PIB. A maior parte deste montante refere-se a negócios fora das porteiras, abrangendo o suprimento de insumos, o beneficiamento/processamento das matérias-primas e a distribuição dos produtos.

Veiga et al. (2001), ressaltam que nos sete censos agropecuários realizados no Brasil desde 1950, a participação dos agricultores que têm menos de 100 hectares nunca se distanciou de $90 \%$ do total de estabelecimentos, e sempre lhes coube $20 \%$ da área, o que indica uma permanência extremamente duradoura desses produtores de pequeno porte por toda a segunda metade do século. Essa permanência no cenário agrícola, apesar dos constantes desafios, mostra que esse segmento está em constante mudança, compondo estratégias de sobrevivência e reprodução, as quais dependem do meio no qual os agricultores familiares estão inseridos.

Atualmente, cerca de $85 \%$ do total de propriedades rurais do país pertencem a grupos familiares. De acordo com a Secretaria de Agricultura Familiar são 13,8 milhões de pessoas em cerca de 4,1 milhões de estabelecimentos familiares, o que corresponde a $77 \%$ da população ocupada na agricultura. Cerca de $60 \%$ dos alimentos consumidos pela 
população brasileira e $37,8 \%$ do Valor Bruto da Produção Agropecuária são produzidos por agricultores familiares. (BRASIL, 2011)

De acordo com Gonçalves e Souza (2011), a definição de propriedade familiar consta no inciso II do artigo $4^{\circ}$ do Estatuto da Terra, estabelecido pela Lei $n^{\circ} 4.504$ de 30 de novembro de 1964, com a seguinte redação: " propriedade familiar : o imóvel que, direta e pessoalmente explorado pelo agricultor e sua família, lhes absorva toda a força de trabalho, garantindo-lhes a subsistência e o progresso social e econômico, com área máxima fixada para cada região e tipo de exploração, e eventualmente trabalhado com a ajuda de terceiros" e na definição da área máxima, a lei $\mathrm{n}^{\circ}$ 8629, de 25 de fevereiro de 1993, estabelece como pequena os imóveis rurais com até 4 módulos fiscais e, como média propriedade, aqueles entre 4 e 15 módulos fiscais.

Abramovay (1992) diferencia a agricultura familiar no interior das sociedades capitalistas mais desenvolvidas como uma forma completamente diferente do campesinato clássico. Enquanto que os camponeses podiam ser entendidos como "sociedades parciais com uma cultura parcial, integrados de modo incompleto a mercados imperfeitos", representando um modo de vida caracterizado pela personalização dos vínculos sociais e pela ausência de uma contabilidade nas operações produtivas. Já a agricultura familiar, segundo o mesmo autor, [...] é altamente integrada ao mercado, capaz de incorporar os principais avanços técnicos e de responder as políticas governamentais [...] Aquilo que era antes de tudo um modo de vida converteu-se numa profissão, numa forma de trabalho (ABRAMOVAY, 1992, p.22-127).

Para esse autor, em the sendo favorável esse ambiente e com apoio do Estado, a agricultura familiar preencheria uma série de requisitos, dentre os quais fornecer alimentos baratos e de boa qualidade para a sociedade e reproduzir-se como uma forma social engajada nos mecanismos de desenvolvimento rural.

A agricultura familiar no Estado de São Paulo apresenta características únicas e próprias de uma região extremamente dinâmica. De acordo com Belik e Rosa de Souza (2009), por ser um estado cuja base está amparada na economia industrial, em transição para uma sociedade de serviços, a agricultura em geral não é percebida entre a população pela sua importância. $\mathrm{O}$ setor agropecuário representa não mais do que $1,6 \%$ do PIB paulista e a mão de obra residente nas áreas rurais $5,7 \%$ do total. Assim quem não está familiarizado com os indicadores do setor rural acaba não se dando conta do peso da agricultura familiar em São Paulo e da sua complexidade e heterogeneidade.

Estes produtores e seus familiares são responsáveis por inúmeros empregos no comércio e nos serviços prestados nas pequenas cidades. A melhoria de renda deste segmento por meio de sua maior inserção no mercado tem impacto importante no interior do país e por consequência nas grandes metrópoles. 
Segundo dados do Censo Agropecuário de 2006 (IBGE), o Estado de São Paulo possuía 151.015 estabelecimentos de agricultura familiar $(66,3 \%$ do total da agricultura) ocupando uma área de 2,5 milhões de hectares (15,0\% dos estabelecimentos). A agricultura familiar ocupava 328.177 trabalhadores ou $36,1 \%$ da mão de obra empregada na agricultura do estado, sendo que mais de $80 \%$ desses trabalhadores teriam algum laço de parentesco com chefe do estabelecimento.

\section{A agricultura na região sudoeste do estado de São Paulo}

O sudoeste do estado de São Paulo tem como principal Região Administrativa (RA) a Região de Sorocaba, que está dividida em cinco Regiões de Governo (RG), que totalizam 79 municípios. São elas: RG de Avaré; RG de Botucatu; RG de Itapeva; RG de Itapetininga; e a RG de Sorocaba. A RG de Sorocaba (RGS) é formada por 18 municípios: Alumínio, Araçariguama, Araçoiaba da Serra, Ibiúna, Iperó, Itu, Jumirim, Mairinque, Piedade, Pilar do Sul, Porto Feliz, Salto de Pirapora, Salto, São Roque, Sorocaba, Tapiraí, Tietê e Votorantim. A sede da Região é o próprio município de Sorocaba, seu maior polo, que concentra $20,2 \%$ da população regional. (SONODA, 2006)

Segundo o Levantamento das Unidades de Produção Agropecuária (LUPA), atualmente a carne bovina é o principal produto regional. Em 2010, o Valor da Produção Agropecuária regional foi de $\mathrm{R} \$ 6,5$ bilhões, ou $14 \%$ do Estado, e a carne bovina contribuiu com 18\% do VPA (Valor da Produção Agropecuária) da região. Outros destaques também podem ser observados para as culturas de cana-deaçúcar, laranja, café, uva, soja, trigo e eucalipto, todas com expressivo crescimento nas últimas décadas na região.

O entorno de Sorocaba, embora tenha a maior parcela de sua área rural ocupada por cana-de-açúcar, detém $60 \%$ da produção estadual de repolho, $51 \%$ da de cenoura e $35 \%$ da de beterraba, o que mostra a grande diversidade agropecuária local. (IPEA, 2005)

Atualmente a região é caracterizada por uma mescla de um pequeno número de agricultores patronais e um razoável número de agricultores familiares. (A agricultura familiar, praticada em $85 \%$ dos estabelecimentos agrícolas do país, caracteriza-se pela diversificação, tanto em produtos, quanto em sistemas de produção e tecnologia, englobando entre 60 e $80 \%$ da produção dos alimentos (vegetais e animais) consumidos pela população, além de matérias primas para diversos fins, como roupas, bebidas, artesanatos, etc.). (SÃO PAULO, 2008)

Segundo informações obtidas em 2012 junto a CONAB e ao Ministério de Desenvolvimento Agrário, através de consultas diretas, a região administrativa de Sorocaba contava com cerca de 30 associações e cooperativas ligadas à agricultura familiar, das quais menos de 20 ainda se encontravam em atuação junto a um número estimado de 2000 agricultores. 


\section{Desafios da agricultura familiar na região: resultados e discussão}

De modo a buscar informações mais precisas sobre as estratégias produtivas e comerciais dessas organizações, foi aplicada uma pesquisa de campo estruturada em visitas e entrevistas, que foram realizadas entre janeiro de 2010 e novembro de 2012 com representantes e funcionários de 10 cooperativas e associações da região às quais os agricultores familiares estão vinculados, selecionadas a partir de uma lista de entidades cadastras pela CONAB para o Programa de Aquisição de Alimentos - PAA, hoje constantes no site da "Rede Brasil Rural", do Ministério do Desenvolvimento Agrário.

Nas visitas também foi possível conhecer as instalações dessas entidades, assim como pomares, hortas, estufas, viveiros de mudas, além das residências de alguns produtores familiares, sendo que parte delas se localizava dentro de assentamentos da reforma agrária.

Um dos aspectos observados foi a simplicidade das instalações dessas entidades, que contrastava em meio a cenários compostos por grandes áreas ocupadas por pastagens e plantações de cana-de-açúcar e eucalipto, da agricultura patronal, com seus galpões imponentes e grandes fazendas, além de condomínios residenciais de alto padrão. A presença dos agricultores familiares também contrastava no aspecto habitacional, como únicos residentes de áreas remotas, cercados por grandes plantações.

Os agricultores residentes nos assentamentos, no entanto, contavam de certa forma com algumas estruturas de apoio mais próximas, como é o caso do assentamento de Porto Feliz-SP, que possui uma escola e um centro de saúde dentro do assentamento, enquanto que os agricultores familiares de uma das associações do município de Iperó, por exemplo, residiam em uma área totalmente isolada e distante de estruturas urbanas, e até mesmo de transporte público.

Outro aspecto observado foi a estrutura administrativa muito simples e de certo modo deficiente presente nessas organizações. A maior parte delas é gerida pelos próprios produtores, através da eleição de um pequeno grupos de pessoas geralmente organizadas em presidente, vicepresidente, tesoureiro e um ou mais diretores para assuntos específicos, sendo que em apenas três cooperativas foi observada a presença de funcionários administrativos, como secretárias. Em nenhuma foi observada a presença de técnicos ou Agrônomo, ausência justificada pela precária situação financeira destas organizações.

Com relação a origem das cooperativas e associações entrevistadas, constatou-se que em quase todas elas o fator principal foi a possibilidade de acesso aos programas de compras governamentais.

Atualmente nove dessas associações e cooperativas estão articuladas na Cooperativa Central de Produção e Abastecimento - CPRA, sediada em Sorocaba, que objetiva facilitar a comercialização dos produtos e a logística de distribuição para os mais de 1000 produtores associados. 
Apesar de contarem com estratégias diversificadas, quase a totalidade desses produtores está envolvida na produção de alimentos, sendo que apenas uma pequena parcela se dedica a produção de gêneros diferenciados como a cana-de-açúcar para o etanol e a madeira, cujas características de produção acabam por limitar sua viabilidade técnica e econômica para a agricultura familiar.

A maior parte dos produtos é comercializada na própria região, através da venda direta em feiras livres ou através dos entrepostos como o CEAGESP (Companhia de Entrepostos e Armazéns Gerais de São Paulo) e o CEAVO (Centro de Abastecimento de Votorantim).

Segundo informações obtidas em entrevista com a diretoria do CEAGESP de Sorocaba, a unidade comercializa cerca de 10 mil toneladas de alimentos por mês, entre frutas, legumes, verduras e cereais, quase todos produzidos por pequenos e médios produtores da própria região, e que tem como destino as feiras-livres, mercados, mercearias e restaurantes da região.

Apesar do número ser expressivo, um grande número de agricultores da região ainda não tem acesso ao CEAGESP, devido à problemas quanto a documentação exigida e aos custos envolvidos, como relatou em entrevista o coordenador do Centro de Abastecimento de Votorantim CEAVO, uma associação criada a partir da necessidade de um grupo de pequenos produtores da região que, por se encontrar em tal situação, comercializava seus produtos em uma rua pública do município. Hoje a associação reúne cerca de 115 produtores de 15 municípios, que se reúnem em uma área alugada para vender seus produtos três vezes por semana, tornando-se uma alternativa local ao Entreposto oficial.

Outro aspecto observado entre as associações e cooperativas entrevistadas, é que apenas duas delas adotam a estratégia de venda direta ao consumidor, através de bancas próprias em feiras-livres (também conhecidas como feiras de rua) no município de Sorocaba. Uma delas, conseguiu um espaço em uma das maiores feiras da região, realizada às quartas e sábados no estacionamento do próprio CEAGESP, que atrai milhares de consumidores, enquanto a outra conseguiu uma banca aos domingos dentro de um parque ecológico, onde vende seus produtos aos visitantes do parque.

Apesar da região contar com produção rural em praticamente todos os municípios, a maior parte dos agricultores familiares concentram-se nas cidades de Capela do Alto, Araçoiaba da Serra, Piedade e Ibiúna. Sorocaba, apesar de ser considerada o centro econômico regional, reúne apenas uma pequena parcela dessa produção nos bairros do Ipaneminha das Pedras, Brigadeiro Tobias, Campininha, Éden, Caputera, Itinga e Caguaçu. Nessas regiões os agricultores criam gado de leite e produzem frutas, verduras, legumes e cereais.

Com relação ao mercado institucional, todas as organizações entrevistadas afirmaram a importância vital da participação nesses programas governamentais, que para algumas cooperativas chega a ultrapassar $80 \%$ 
das vendas anuais. Hoje, tais organizações tem procurado se especializar no atendimento desse mercado institucional, reunindo knowhow sobre preparação e organização de documentos, elaboração de propostas e planos de vendas, bem como sobre a busca por oportunidades de vendas, algo que dificilmente seria possível para produtores individuais ou nãocooperados.

Para o atendimento do PAA, por exemplo, as organizações precisam manter cadastros atualizados de todos os seus associados, sobre tudo o que produzem e podem produzir, além de toda a documentação necessária, como é o caso dos registros da DAP (Declaração de aptidão ao Programa Nacional da Agricultura Familiar PRONAF) de cada agricultor, emitidos por órgãos oficiais como a CATI (Coordenadoria de Assistência Técnica Integral) da Secretaria de Agricultura e Abastecimento do Estado, ou mesmo pelo Sindicato Rural de Sorocaba.

Para a venda através do PNAE e do PPAIS, as organizações devem estar atentas às chamadas públicas, divulgadas periodicamente pelos municípios, no caso do PNAE, ou pelo governo do Estado, no caso do PPAIS e também do PNAE para as escolas estaduais. Além disso, devem estar preparadas para elaborar propostas consistentes de vendas, e estar atentas aos limites financeiros impostos por esses programas para cada produtor envolvido. No PNAE, por exemplo, atualmente existe um limite de $\mathrm{R} \$ 20$ mil por DAP ao ano, enquanto que no PPAIS o limite é de R $\$ 12$ mil. No PAA os limites variam de $\mathrm{R} \$ 4,5$ mil a $\mathrm{R} \$ 9$ mil de acordo com a modalidade.

Após firmados os contratos de vendas, as organizações devem garantir o cumprimento do cronograma de entrega estabelecido. Atrasos e irregularidades nas entregas geralmente são punidos com multas e até mesmo suspensão dos contratos, o que requer um elevado grau de organização interna e de gestão sobre seus associados ou cooperados. Outro fator decisivo nesses contratos é a fiscalização sobre os limites financeiros de vendas. Algumas das cooperativas entrevistadas alegaram ter se atrapalhado muito com essa questão no início da participação nesses programas, chegando até a ficar impossibilitados de cumprir o cronograma de entregas devido a erros no cálculo dos limites financeiros de vendas.

Desde que ingressaram nestes programas, tais organizações conseguiram contratos de fornecimento com praticamente todos os municípios da região, além de outros mais distantes, como São Bernardo do Campo, na região do grande $\mathrm{ABC}$ paulista, e Ribeirão Preto, no nordeste do estado, apesar dos custos mais elevados com o transporte.

Os contratos de fornecimento firmados envolveram frutas, legumes, verduras e mel, em quantidades e embalagens variadas. Grande parte para o atendimento da alimentação escolar. Recentemente, com a abertura do PPAIS, a oportunidade foi ampliada para o atendimento aos hospitais, penitenciarias, e outras instituições mantidas pelo estado. 
Além do mercado institucional, boa parte dessas organizações tem em planos estratégias de vendas diretas ao consumidor final e a quitandas e supermercados da região, mas ainda tem encontrado dificuldades quanto a aderência dos próprios agricultores a essas estratégias, que ainda preferem correr o risco das vendas individuais direta ou indiretamente, na busca de maior rentabilidade, algo que tem sido trabalhado sistematicamente nas reuniões com os mesmos.

\section{Considerações Finais}

Este estudo buscou discutir a abertura do mercado institucional diante da perspectiva de associações e cooperativas de agricultores familiares da região sudoeste do estado de São Paulo. Verificou-se que, apesar dos entraves encontrados na abertura de um espaço marcado por grandes empresas e fornecedores de alimentos, as políticas de compras públicas institucionais como PAA, PNAE e PPAIS estão alcançando resultados positivos no que se refere a sustentabilidade econômica dos agricultores, bem como na estruturação dos grupos formais em que estes se encontram associados.

Por outro lado, ressalta-se que boa parte dos problemas enfrentados pelos agricultores da região está relacionada à falta de assistência técnica nas propriedades, regularização fundiária, e falta de acesso às linhas de crédito e financiamento. Além desses, também se nota a precária situação das moradias, dos acessos, dos meios de transporte público, dos sistemas de comunicação, do acesso às informações, além dos riscos ocupacionais e da distância entre os locais de trabalho e os serviços de saúde pública, acessados por essas famílias.

Do ponto de vista organizacional, chamam atenção as dificuldades que envolvem o planejamento e a gestão das organizações desses agricultores, que mesmo diante de grandes oportunidades comerciais como as oferecidas pelos programas governamentais de aquisição de alimentos para entidades beneficentes e escolas, ainda esbarram no baixo envolvimento dos próprios associados e cooperados, que ainda comercializam a maior parte de sua produção por intermédio de atravessadores.

De modo a contribuir para a melhoria das questões levantadas neste estudo, e apressar a solução para os problemas aqui expostos, sugere-se inicialmente que os órgãos de apoio governamental como as Casas da Agricultura, que representam a Coordenadoria de Assistência Técnica Integral - CATI nos municípios, sejam fortalecidos com recursos técnicos, humanos, físicos e financeiros, para que possam aprimorar seus programas de apoio aos produtores familiares, de forma que estes possam receber um aporte especializado para melhorar a gestão produtiva de seus negócios e de suas associações. A demanda por assistência técnica nas propriedades é grande, e a situação financeira dos agricultores e de suas associações e cooperativas tem limitado a contratação direta de técnicos, agrônomos e veterinários, o que põe em risco seus negócios, tanto por questões referentes a baixa produtividade, ligada a fertilização incorreta dos solos, falta de 
irrigação e de combate a pragas e doenças, quanto de qualidade fitossanitária de seus produtos. Além disso, é grande também a demanda por informações sobre planejamento de vendas e logística, que poderia ser suprida através de encontros, oficinas e workshops direcionados a esse público específico, promovidos por órgãos como o SENAR, ou até mesmo pelos Sindicatos Rurais, em parceria com Universidades da Região.

De modo análogo, é imperativo que as associações e cooperativas deem um passo a frente em direção à profissionalização de suas estruturas organizacionais, incorporando em seus quadros profissionais treinados $\mathrm{e}$ capacitados tanto para lidar com os detalhes burocráticos das compras públicas, quanto para realizar planos estratégicos que possam levar essas organizações a conquista de melhores posições no mercado. A profissionalização, apesar de demandar investimentos e de aumentar os custos operacionais, tem se mostrado o caminho mais seguro para a melhoria da situação econômica dessas organizações, o que é um requisito fundamental para se aumentar a fidelidade dos agricultores associados, e para diminuir gradativamente sua dependência com relação à assistência do Estado.

\section{REFERÊNCIAS}

ABRAMOVAY, R. Paradigmas do capitalismo agrário em questão. São Paulo: HUCITEC/UNICAMP, 1992, 275 p.

BELIK, W E ROSA DE SOUZA, L R Algumas Reflexões sobre os Programas de Alimentação Escolar na América Latina. Planejamento e
Políticas Públicas. São Paulo, IPEA no. 33 jul/dez 2009, pp103-122.

BRASIL - Ministério da Agricultura, Pecuária e Abastecimento (MAPA). Programa de Aquisição de Alimentos (PAA). Brasilia, 2009. Disponível em: < http://www.agricultura.gov.br>. Acesso em: 06 out. 2011.

BRASIL - Ministério do Desenvolvimento Agrário(MDA). Secretaria de Agricultura Familiar. Programa Nacional de Alimentação Escolar - PNAE. Brasilia, 2010. Disponível em: < http://www.agricultura.gov.br>. Acesso em: 08 ago. 2012.

CAllado, A. A. C. Agronegócio. São Paulo: Atlas, 2006.

GONÇALVES, J. S.; SOUZA, S. A. M. Agricultura familiar: limites do conceito e evolução do crédito. Artigos: políticas públicas. Instituto de Economia Agrícola $<$ http://www.iea.sp.gov.br Acesso em: 10 jul. 2011.

IPEA - INSTITUTO DE PESQUISAS ECONÔMICAS APLICADAS. Radar Social. Brasília, IPEA, 2005. 132 p. MAWHINNEY, M. Desenvolvimento Sustentável: uma introdução ao debate ecológico. São Paulo: Edições Loyola, 2005. $231 \mathrm{p}$

\section{SÃO PAULO (Estado). Projeto LUPA}

2007/2008: Levantamento censitário de unidades de produção agrícola do Estado de São Paulo. São Paulo: SAA/CATI/IEA, 2008.

SONODA, Érica Cátie. Evolução Econômica e Mudanças na Estrutura Produtiva da Região Administrativa de Sorocaba (1980-2005). Universidade Estadual de Campinas - Unicamp, Instituto de Economia. Campinas, 2006.

VEIGA, J. E. ; FAVARETO, A. ; AZEVEDO, C.M.A. ;BITTENCOURT, G. ; VECCHIATTI, K. ; MAGALHÃES, R. ; JORGE, R. O Brasil rural precisa de uma estratégia de desenvolvimento. Brasília: Convênio FIPEIICA(MDA/CNDRS/NEAD), 2001. 108 p. 